\title{
Does Fish Welfare Matter? On the Moral Relevance of Agency
}

\author{
Frederike Kaldewaij
}

Accepted: 14 December 2011/Published online: 3 February 2012

(C) The Author(s) 2012. This article is published with open access at Springerlink.com

\begin{abstract}
To determine whether fish welfare matters morally, we need to know what characteristics or capacities beings need to have in order to be morally considerable, and whether fish have such characteristics. In this paper I discuss a group of theories, Kantian practical reasoning theories, in which agency (or practical rationality) is traditionally thought to be a necessary condition for moral considerability. An individual must have quite sophisticated capacities to be a (moral) agent in such theories: she must be able to act on rational principles. It seems unlikely that nonhuman animals such as fish have such capacities. I argue, however, that on the basis of certain Kantian arguments, moral agents have reason to accept duties to nonrational animals if they are agents in a much less demanding sense: if they are motivated to pursue the objects of their desires. If fish have this capacity, their welfare matters morally.
\end{abstract}

Keywords Animal ethics $\cdot$ Kantian moral theory $\cdot$ Agency $\cdot$ Practical reason $\cdot$ Fish

\section{Introduction}

Does fish welfare matter morally? To answer this question, we have to determine what characteristics or capacities beings need to have in order to be morally considerable, and whether fish have such characteristics. Different proposals have been made for characteristics that are necessary conditions for moral considerability, for example being alive, being sentient (that is, being able to feel pain and pleasure), or being an agent (a practically rational being). If life is the ticket to mattering morally, then fish are in, but so are plants or even bacteria. In the wellknown moral theory of utilitarianism, animals who can feel pain and pleasure stand

F. Kaldewaij (ه)

Philosophy Department, Utrecht University, Janskerkhof 13a, 3512 BL Utrecht, The Netherlands

e-mail: Frederike.Kaldewaij@phil.uu.nl 
out from the rest of living beings. If fish have these capacities then their welfare is to be considered equally in this theory (see e.g., Singer 1999). But in Kantian practical reasoning theories, ${ }^{1}$ it is usually thought that only agents, that is, practically rational beings, matter morally. This at first sight seems to be bad news for fish.

There are important differences between utilitarianism and Kantian practical reasoning approaches. In utilitarianism, the right thing to do is regarded as that which maximizes the good: the collective welfare of everyone. Duties not to harm animals and to further animal welfare follow naturally from the basic premises of this theory. In Kantian theory, however, moral actions are not regarded as means to bring about a maximally good state of affairs. Kantian theorists try to show that a certain moral principle (from which other duties can be derived) is founded in practical reason, so that all rational beings have to accept this principle. In Kantian theory, certain actions ${ }^{2}$ can be wrong in themselves, even if they produce more welfare than another possible action. It is sometimes seen as an advantage of Kantian theory that it can account for the widely shared intuition that it can be wrong to, for example, sacrifice individuals or minorities, even if this maximizes the welfare of everyone taken together.

Traditionally it has been thought that, in Kantian theory, the group of beings who are moral agents and the group of beings who are morally considerable is coextensive. Moral agents must have specific capacities: they must be able to act on principles that are grounded in practical reason. If only moral agents can have moral status, this would mean that nonhuman animals and certain intellectually disabled human beings and infants are not morally considerable. ${ }^{3}$ There may be discussion about relatively cognitively complex nonhuman animals like apes, but it seems difficult to believe that fish can be practically rational.

But is it really the case that we can only have duties to practically rational beings in Kantian theory? In this paper I will try to offer some insight into the Kantian view of the nature and justification of morality. ${ }^{4} \mathrm{My}$ central aim is to argue for a specific claim. I will argue that even though, in these theories, to be a moral agent (and

\footnotetext{
${ }^{1}$ I have borrowed this term from Darwall et al. (1992), and use it to refer to theories who attempt to give an ultimate justification for categorical duties, by showing that these are grounded in practical reason. There is a lot of debate about how Kant's own moral philosophy should be interpreted. Kant in the third chapter of the Groundwork of the Metaphysics of Morals (Kant 1998 [1785]) seems to attempt to give such a fundamental justification of the Categorical Imperative. Some hold that he continued to regard this justification as succesful in his later work Critique of Practical Reason (Kant 1997 [1788]; e.g., Pauline Kleingeld in Reath and Timmermann 2010:55-72), but others think Kant in the later work admitted such a fundamental justification of the moral law is impossible (e.g., Jens Timmerman in Reath and Timmermann 2010:73-89). Modern Kantian practical reasoning theorists offer an interpretation of Kant's justification or their own fundamental justification of categorical duties; examples are e.g., Nagel (1978), Korsgaard (1996), and Gewirth (1978). See "Determining to whom we have moral duties" section and note 6 for very brief descriptions of these arguments.

2 To be more precise: principles upon which one acts (in Kant's own terminology: "maxims"), which contain not only a description of the action one performs, but also the reason why one performs the action (e.g.: "I will lie whenever this is to my best advantage").

3 In the sense that we do not have direct duties to them (see "Indirect and direct duties" section for an explanation of the distinction between direct and indirect duties).

${ }^{4}$ Kantian theories are notoriously difficult, and in this paper I will not be able to do justice to the intricate argumentation of different Kantian authors. In my PhD thesis "Agents and animals: the possibility of
} 
therefore morally responsible) a being has to be practically rational, certain Kantian arguments can be used to defend the claim that to be morally considerable (so that moral agents have duties to you), a being has to be an agent in a much less demanding sense. It is sufficient for moral considerability that a being can purposefully pursue the objects of desires (such as a desire not to feel pain). Note that this is a controversial claim, which is at odds with traditional Kantian views, although the contemporary Kantian philosopher Christine Korsgaard has recently defended a similar claim (in e.g., Korsgaard 2005, 2011). Of course, in this paper I can only offer a sketch of my argument, but if this argument is valid, then we have duties to fish if they have such capacities.

\section{Kantian Practical Reasoning Theories and Categorical Rational Requirements}

Kantian practical reasoning theorists share a specific view of the nature of moral duty and how moral duties can be justified. They regard moral requirements as categorical requirements that are founded in practical reason. Let me explain both of these terms in turn.

I will begin with the latter term: "practical reason." We can distinguish practical uses of our rational capacities from theoretical uses. We for instance use reason for theoretical purposes when we attempt to gain knowledge of how things are (as in empirical science) or when we do mathematics or formal logic. The practical use of our rational capacities, in contrast, is the use of reason in action. It is about determining what we should do. An example is instrumental reasoning. If you have the purpose of getting fresh air, and the only way to get fresh air is to open a window, it is rational to open a window and would be irrational to close it. So instrumental reasoning concerns taking the necessary means to your end (or giving up your end).

Sometimes people use the term "rational action" for action that will further your self-interest. A rational requirement to do what will further your self-interest is called a "prudential requirement." So-called Hobbesian practical reasoning theories (Darwall et al. 1992:131-134), named after Thomas Hobbes, a 17th century social contract theorist, argue that it is ultimately in all of our interest to accept certain social rules even if it may not be in our immediate interest to adhere to these rules. For instance, in a given situation it may be in my immediate interest to lie, but if everyone did this all the time, trust would break down, and this would not be in my self-interest. So in this sense it may be thought to be rational for all of us to accept certain rules, such as a rule of telling the truth.

These Hobbesian theorists seem to provide a plausible story about how certain social or moral rules historically came into existence. But they cannot capture an important element of common thought about morality. It is commonly thought that morality and self-interested behavior are two very different things, and that it even

Footnote 4 continued

justifying duties to animals in Kantian practical reasoning theories" (preliminary title; forthcoming 2012)

I analyze these arguments in much more detail. 
detracts from the moral worth of your action if you ultimately do it because it is in your interest, rather than because it is the right thing to do. It may for example be in the interest of the powerful to enslave the weak, yet we would still consider this to be morally wrong. Kantian practical reasoning theorists follow Kant in emphasizing the concept of duty, and regarding our moral duty as independent of what is in our interest. We should do our duty simply because it is our duty, and not (directly or indirectly) for the sake of some self-serving end.

To understand the concept of a categorical requirement, it is useful to contrast this with the instrumental and prudential rational requirements mentioned above. All these requirements are supposed to be valid for all rational beings, (they are "universal"), but there is an important difference. Instrumental requirements have the form: "if you want to achieve some end $y$, and $x$ is the necessary means to $y$, do $x$." Prudential requirements similarly say: "if $y$ is in your interest, do $y$." Categorical requirements, in contrast, do not contain such an if, they are not only valid when a specific condition holds: that acting in the way prescribed will further some (nonmoral) end we desire to achieve or our happiness. They simply say: "do $y$," where y stands for a moral duty. Kantian theorists attempt to show that there are categorical requirements that all moral agents (who are in the relevant circumstances) must rationally accept.

At first glance, it would appear that it is more probable that we can justify moral duties to animals in Kantian theories than in Hobbesian theories. After all, it is not in our self-interest to accept moral constraints in our interactions with animals (the same thing, by the way, goes for our treatment of physically or intellectually handicapped human beings). If there are no moral constraints in our treatment of animals, we can simply eat them, use them in scientific experiments, etc., without qualms, and people clearly have an interest or desire in doing such things. In Kantian theory our moral duties are not justified on the basis of our self-interest, and this seems to leave a possibility open for duties to animals. But can Kantian arguments for duties to others only support duties to rational beings, or also duties to animals?

\section{To What Kind of Beings do we have Moral Duties?}

Moral Agency and the Justification of Duties

Kantian practical reasoning theorists attempt to give a fundamental rational justification of a moral principle. The arguments generally start from a certain conception that, these theorists argue, moral agents must have of themselves, such as "I am a (free/rational) agent." It is then argued that this self-conception rationally commits them to a certain basic categorical requirement. All moral duties can be derived from this basic requirement. ${ }^{5}$

\footnotetext{
5 See "Determining to whom we have moral duties" section and foot note 6 for a brief description of some such arguments.
} 
It is usually thought that we, on the basis of these arguments, are only required to accept duties to beings who are also practically rational. Moral agents, in Kantian theory, must have specific, quite sophisticated, capacities. Animals are sometimes said to be capable of moral behavior, for instance when they engage in seemingly altruistic behavior. But this is not enough to count as moral agency in Kantian theory. The idea is that natural dispositions we have, such as sympathy for others, may explain or describe what we do, but cannot give us a justification for what we morally ought to do. According to these Kantian theorists, we, as practically rational beings, have moral duties because we rationally have to accept certain duties. This is the central idea of autonomy, which is not simply understood as simply doing what one (perhaps after reflection, and sufficiently informed) wants, but as self-legislation of moral duty.

Moral agents, then, must at least be capable of not simply acting on the strongest desire of the moment. They must be able to act on rational requirements, even if they lack an (unmotivated) desire to do what the requirement tells them to do. Note that such capacities are also necessary to be able to act on the instrumental or prudential requirements I mentioned above. At any given time I may prefer eating cookies to exercising. To be able to act prudentially rationally, I have to be able to suppress my stronger desire and act on a judgment about what is best for me. But when we act on these requirements we eventually still act for the sake of some end that is connected to our sensuous nature: to our feelings and desires, which are related to our physical and psychological needs.

However, as explained above, when we act on a categorical requirement, we act in a way that is rationally required regardless of what our own desires might be or what is in our self-interest. We must be able to do our duty simply because it is the right thing to do. It seems unlikely that nonhuman animals, especially relatively cognitively simple animals like fish, have the abilities that are required to be able to do this. It is often assumed that animals act on the strongest desire of the moment, although this seems to be an overly simplistic way of thinking about animal behavior. Although certain animals may be capable of an informal kind of instrumental reasoning (Bermudez 2007:130), it seems implausible to assume that they can act on the basis of insight into the validity of a formal rational principle, such as a hypothetical or categorical requirement. Such insight seems to require the possession of a (somewhat complex form of) language (Bermudez 2007:131).

\section{Indirect and Direct Duties}

As I mentioned above, the received view is that Kantian arguments can only support duties to rational beings. Even if this is the case, this does not necessarily mean that we can just treat nonhuman animals such as fish any way we please. Kant himself has argued that we should not treat animals cruelly because this gradually "uproots a natural predisposition [sympathy] that is very serviceable to morality in one's relations to other men," by which he means rational beings (Kant 2000 [1797]:192-193, 6:443). But why exactly would our moral duties ultimately be concerned with how we treat rational beings?

In this paper I am interested in the question whether we can have duties to animals, that is, direct duties, not just duties regarding animals: duties of which 
animals are the beneficiaries, but which are ultimately duties to rational beings. I will interpret a "duty to others" as a duty we have to treat them in a certain way which is not just a means to fulfilling our duty, but is in itself a duty. For instance, we may have a moral duty to preserve a Van Gogh painting. What makes this an indirect duty is that the reason why we have this duty ultimately refers, say, to a presumed interest of contemporary and future human beings to be able to aesthetically appreciate this painting. If these human beings dropped out of the picture, then we would have no duty whatsoever with regard to this painting. However, if we have a direct duty to animals, to, say, not unnecessarily harm them, it is in itself wrong to harm animals, and not, for example because it may lead us to be cruel to other rational beings. If other rational beings dropped out of the picture, we would still have the duty to treat animals in this way. We could perhaps say that if we have a direct duty to animals, this means that treating animals in such a way is a moral end in itself, and not only a means to another moral end (treating rational beings in a certain way).

\section{Determining to Whom we Have Moral Duties}

As I mentioned above, Kantian arguments that attempt to give a fundamental justification for moral duties to others start with a certain conception that we, moral agents, have of ourselves and derive moral duties from this conception. Different Kantian authors have suggested different conceptions and what implications can be derived from this. ${ }^{6}$ Kant himself argues that all rational agents have to regard themselves as free: as undetermined by their natural desires, and capable of acting on a law that is constitutive of their rational will as such. This law, he argues, is the moral law: "act in accordance with that maxim through which you can at the same time will that it become a universal law" (Kant 1998:31; 4:421). ${ }^{7}$

I here do not have the space to discuss the difficult question of how this principle is justified exactly, ${ }^{8}$ but to understand the general idea of the universalizability test,

\footnotetext{
${ }^{6}$ E.g., Thomas Nagel argues that to avoid a kind of solipsism, we have to understand ourselves as "merely a person among others equally real" and argued that therefore all genuine reasons for action are objective or agent-neutral: they may not contain a "free agent variable," referring exclusively to the agent who acts, such as: "I will avoid harm to myself." Instead they must e.g., have the form "I will avoid harm to anyone" (Nagel 1978); Christine Korsgaard offered an influential interpretation of Kant's Formula of Humanity, and argued that beings who understand themselves as acting rationally necessarily confer value on rational choice (or "humanity") (in e.g., Korsgaard 1996). She has more recently also argued that we must also confer value on the natural good of animals (see e.g., Korsgaard 2005, 2005, 2011); Alan Gewirth argues that every agent has to claim rights to the goods that are instrumentally necessary for the successful pursuit of purposes in general: freedom and well-being. As we claim these rights merely because we are agents, we have to regard being an agent as a sufficient basis for having such rights, and therefore also have to attribute rights to the generic goods of agency to other agents.

7 In the text that follows I use Kant's Formula of Universal Law (FUL) as an example to make my point. I do this because I think Kant's FUL may be more familiar to readers than the arguments by e.g., Nagel, Korsgaard, and Gewirth. However, I think the same basic argument can be made with regard to the arguments of these contemporary authors, and I will here and there in footnotes refer to them.

${ }^{8}$ In this paper, I do not address the difficult question of whether these Kantian arguments are valid. I only ask the question: if these arguments are otherwise valid, can they only justify duties to rational beings, or also to animals?
} 
it may be helpful to remember that, for Kant, morality may not be subordinated to, or made a function of, self-interest. Moral duties are duties for all rational beings, and the central idea is that we do not make an "exception [...] for ourselves" (Kant 1998:34; 4:424). The principle of not helping others in need when one does not feel like it, for instance, is something we cannot will as a universal law. If I will my principle as a universal law, this would mean that I will a situation in which all practically rational beings refrain from helping others in need, which would mean that they would also not help me if I needed help. As there may very well be moments when I want and need the help of others, I cannot will this. Therefore I have to regard this maxim as morally impermissible, and have to accept the opposite maxim: helping others in need.

Some authors do not regard this way of understanding the moral test as satisfactory, as it makes the specific moral duties we have dependent on what we happen to will or desire. (Note that the general principle, the Formula of Universal Law, still applies to all rational beings and is as such unconditionally necessary). Someone could in principle, it seems, accept that she never be helped in need herself, if this means she does not have to help others in need either. These authors have attempted to make a stronger claim. ${ }^{9}$ As I mentioned above, the principle of instrumental reason says: if you want to achieve some end, you have to take the necessary means to this end. These authors have pointed out that whatever ends we want to fulfill, we need certain goods to be able to do so: e.g., our freedom, our life, a certain amount of well-being. Regardless of what ends I want to fulfill, I cannot rationally will a situation in which I do not have these goods. Therefore no rational agent can accept a principle of harming others or never helping others in need, unless she is prepared to give up the pursuit of ends altogether.

Above I described the principles the agent has in quite general terms, say of not helping or harming others because one feels like it. But who exactly are these others? Does the category of beings to whom we have these duties include only practically rational beings (agents), or perhaps a subset of rational beings, or nonrational animals too $?^{10}$ The problem of the description of the principles that underlie our actions is a familiar one in Kantian theory. I can think of all sorts of clever ways to describe my principle to avoid it backfiring on me when I universalize it. For example, I cannot will a principle of not harming others because this is in my self-interest as a universal law, but I can will a principle of harming only beings with a different skin color than myself as a universal law. The test requires us to universalize our principles, which

\footnotetext{
${ }^{9}$ Barbara Herman makes an argument like this in the context of the Formula of Universal Law (Herman 1993:52-62) and Alan Gewirth makes a very similar argument, that is not dependent on the validity of Kant's Formula of Universal Law (see foot note 6).

${ }^{10}$ It may be thought that, at least in Kant's own theory, this issue is settled by the Formula of Humanity (FH): we have to use "humanity" (rational nature) as in both ourselves and other beings as an end in itself. My question, though, is precisely why we have to accept duties to only practically rational beings. The justification of the FH has been interpreted in different ways. In my PhD thesis (see foot note 4), I argue that certain arguments in support of the FH, which regard our "humanity" as associated with our moral autonomy, suffer from fundamental problems. Korsgaard has offered an influential interpretation of the argument for the FH and associates humanity with "setting ends" in general, including nonmoral ends. She now also uses this argument to support duties to nonrational animals (see foot note 6), and her argument is in line with the basic argument I present in this paper.
} 
means willing that other rational agents act on this maxim too, but that does not yet settle whom exactly we have duties to.

It is important to note, though, that this is not a prudential argument, although it in certain ways looks like one. While the argument does refer to what we must rationally accept, given that we have certain ends (e.g., that we want to avoid suffering) or given that we pursue any ends at all, the idea is not, as in Hobbesian practical reasoning theories mentioned above, that we accept certain rules because they are in our mutual self-interest. As I remarked above, it is about not making an exception for yourself. My universalizing my maxim does not make it the case that everyone will act as I am acting: it is just a thought experiment to determine what categorical requirements moral agents who are not merely rational, but also have ends connected to their sensuous nature, have to accept. We can describe our principle in a way that will allow ourselves to get off the hook when the principle is universalized, but the question is whether we are then still accurately portraying what our underlying principle is, or just manipulating it in a certain way to suit our self-interest. We should not include details in our principles that do not play an actual role in our motivation.

So can we determine in a non-arbitrary way to whom we have moral duties? Say that you claim that the principle that underlies your action of harming someone, is "I will harm people who have a different skin color than I have, when this in my self-interest." You can, strictly speaking, universalize this principle. But then we can ask you what would happen if you turned out to have ancestors with this skin color. And then you have to realize you would have to regard it as impermissible for others to harm you, because you would not want to be treated like this, or because you cannot rationally will to be treated like this, since you cannot regard it as permissible that you are deprived the generic means for any of your ends. ${ }^{11}$ Having a certain skin color plays no role whatsoever in the reason why you regard it as impermissible for others to treat you in a certain way. As long as you want to fulfill certain purposes you would still regard this as impermissible.

Can we also use this kind of argument to support duties to nonrational animals? Only rational beings have to accept certain moral principles. The question, however, is what moral principles they exactly have to accept. We can ask you: what if you were to lose your rational capacities at some point in future, would you accept that it was permissible for us to harm you then? (see also Korsgaard 2005:104; Werner 2003:68-76). Again, the point of this thought experiment is not to show that it is not in your interest to accept a moral rule that harming nonrational beings is allowed because you might lose your capacity of reason. Rather, the idea is of making us attentive to the reason why we regard certain treatment of ourselves as morally

\footnotetext{
11 This strategy of showing that arbitrary limitations of the scope of our moral duties are unjustified is used by different Kantian authors, but most explicitly by Gewirth, in his "Argument from the Sufficiency of Agency" (1978:110). You have to accept that as long as you are an agent, even if you do not have certain special characteristics (such as being exceptionally intelligent or being called "[insert your own name here])," you would claim the generic rights, because you would need the generic goods for your successful pursuit of purposes in general. Therefore, we must regard being an agent as a sufficient condition of having the generic rights. In my PhD thesis (see foot note 4) I argue that, if Gewirth's argument is generally successful, we are rationally required to claim the rights ultimately because we want to fulfill our purposes, which is a characteristic we share with certain nonhuman animals.
} 
problematic. This is not because we are rational, but because we are beings who e.g., do not want to suffer or want to achieve nonmoral ends in general.

Nonrational animals themselves, of course, only avoid those things they are averse to and pursue things they desire, they do not connect any moral conclusions to this. We, rational animals, (these authors argue) do necessarily have to accept certain moral duties when we pursue nonmoral ends. These thought experiments show us that we must regard e.g., making beings suffer or harming them as in itself morally wrong, regardless of whether we or anyone else is the one suffering. ${ }^{12} \mathrm{We}$ cannot make any arbitrary limitations with regard to who has moral status in our personal favour. We must regard it as wrong to harm anyone who can be harmed in the relevant respect: who can for instance suffer (an end we wish to avoid), or who requires certain generic goods to be able to successfully pursue any ends.

\section{The Relevance of (Moral) Agency}

Above I argued that, while only moral agents have to accept certain moral principles, we do not have to accept certain moral principles simply because we are moral, rational agents. Note that the universalizability test is not about what we can morally will or accept as a universal law. This would make the test viciously circular, as it is supposed to show us exactly what principles are morally acceptable, or what moral ends we must adopt (see also Werner 2003:104). Instead, we cannot will a universalized principle of harming others whenever this is in one's selfinterest because we simply do not want to be harmed ourselves, or because we have any other nonmoral ends. Such ends are ends we desire and actively set out to fulfill, and could range from "I do not want to suffer severe pain" to "I want to become a moral philosopher." We cannot will principles that, when universalized, interfere with our being able to fulfil any such ends. Even if we turned out to lack (or knew we were about to lose) a certain specific characteristic (a certain skin color; the capacity of reason), but would have certain nonmoral ends, we would still regard such treatment of ourselves as wrong. Therefore we have to accept that interfering with the nonmoral ends of beings, whoever they are, for the sake of one's selfinterest, is morally problematic as such.

However, it may be thought that animals cannot pursue nonmoral ends in the same way that rational beings can, and that this is morally significant. Animals are not only not moral agents, they are not agents at all, in the sense we normally use this term. They cannot control their actions in the same way that we can, but seem to act on their strongest desires. We can, for example, choose to exercise because it is the best thing for us, even though we would much rather eat cookies. But as I pointed out above, when we act on instrumental or prudential requirements, the ends

\footnotetext{
12 Barbara Herman argues that her argument (see foot note 9) cannot support duties to animals because animals cannot be part of a community of mutual aid: we cannot count on them to help us in need (Herman 1993:62). It is unclear why their being able to help us would be morally relevant. As we cannot universalize a principle of never helping others in need, we have to accept that such a principle is morally unacceptable, and accept the opposite principle of at least sometimes helping others in need. As I argue in this paper, it is not about what principles are in our self-interest, but about what principles we must consider to be morally wrong in themselves.
} 
we set are ultimately connected to our sensuous nature. "Rational" desires we have, such as the desire to exercise, ultimately make sense in the light of other desires that we have, such as not wanting to get ill and suffer; or any other desires we can only satisfy if we have our health. Such ends are not prescribed by reason but connected to our physical and psychological needs. Although there is a difference in how rational beings and nonrational animals go about pursuing nonmoral ends, what ultimately motivates them is similar.

I am not claiming that differences in the way human beings and animals pursue ends are morally irrelevant, though. For instance, when an adult human being smokes, we must assume she knows what she is doing and judges the benefits of smoking to be worth the health risks involved. If we do not assume this, we may well be imposing our own value system on her. We cannot assume the same thing when a small child or an ape smokes, as they lack the capacities to know the possible consequences of what they are doing for other ends they care about (feeling well, doing things which require good health). We may, consequently, have reason to treat adults and human children and animals in different ways (e.g., to ask informed consent for medical procedures or interventions of adult human beings, but not of small children), but the point I wanted to make here is that there seems to be no reason to think that their suffering or pursuit of ends of their desires is not as morally relevant as ours.

We, then, have certain duties to animals if they desire and purposively pursue certain objects or states of affairs (e.g., to avoid suffering). Such capacities are much less complex than those involved in moral and prudential agency. The latter, more sophisticated kinds of agency seem to require the capacity for second-order thought: thinking about one's desires and (instrumental) beliefs, and the ability to construct valid arguments from such desires and beliefs to action plans. It seems that a being must possess language to be able to have such capacities (Bermudez 2007:131). This, however, does not seem to be necessary in order to be an agent in the less demanding sense of purposefully pursuing objects of desires. Bermudez argues we have reason to use psychological explanations for the behavior of animals if this is not an inflexible response to a stimulus (2007:129). Such explanations are applicable if there is an instrumental component in the psychological states of the animal (which include a desire, such as the desire to eat) that give rise to actions. Such an instrumental component can have the form of a belief (a nonlinguistic analogue to "the food is in the tube") or an immediate perception (that the food is in the tube). There are sources that seem to support that certain species of fish show behavior that is flexible and seems to involve such instrumental components (e.g., Kuba 2010; Laland 2003), but of course much more research is needed by biologists to determine whether this is the case and for which species of fish, and philosophers of mind can help interpret the meaning of such behaviors (see part I in this special issue for relevant discussions).

\section{Implications}

In the introduction to this paper, I pointed out some differences between utilitarianism, in which the morally right thing to do is what maximizes the 
welfare of everyone taken together, and Kantian theory. I have now argued that animal welfare can be directly and in itself morally relevant in Kantian theory. This might be thought surprising. Aren't the implications of these Kantian arguments close to utilitarianism? I have argued that it follows from these Kantian arguments that moral agents have to regard, for example, a principle of harming others for the sake of self-interest as morally unacceptable as such. In utilitarian theory, if animal interests are weighed equally to human interests, it can in certain cases be justified to harm animals for the sake of self-interest: when our combined interests in doing so outweigh the suffering of the animals involved. If duties to animals indeed follow from these Kantian arguments, though, harming animals for the sake of self-interest would be morally impermissible. This would in most cases make the use of sentient, desiring animals for the sake of food production morally problematic.

\section{Conclusion}

Only those who have the capacities required to be a moral agent are morally responsible. Nonrational animals do not have to accept formal rational requirements as they cannot understand such requirements (this is known as the principle "ought implies can"). It could still be, in Kantian practical reasoning theories, that we have to accept moral requirements that involve treating animals in a certain way, such as not harming them. Since the reason why we cannot accept a universal principle of harming others when this in our self-interest is based on e.g., our not wanting to suffer or needing certain basic goods in order to be able to successfully pursue any end we desire to fulfill, it seems to be arbitrary to exclude nonrational animals who also have such desires from the scope of these duties. If fish have such desires, we also have these duties to them.

Acknowledgments I would like to thank Bernice Bovenkerk, Lonneke Poort and Micha Werner, as well as the anonymous reviewers of an earlier version of this paper for their helpful comments.

Open Access This article is distributed under the terms of the Creative Commons Attribution License which permits any use, distribution, and reproduction in any medium, provided the original author(s) and the source are credited.

\section{References}

Bermudez, J. L. (2007). Thinking without words. New York: Oxford University Press.

Darwall, S., Gibbard, A., \& Railton, P. (1992). Toward Fin de siècle ethics: Some trends. The Philosophical Review, 101(1), 115-189.

Gewirth, A. (1978). Reason and morality. Chicago: University of Chicago Press.

Herman, B. (1993). The practice of moral judgment. Cambridge: Harvard University Press.

Kant, I. (1997). [1788] Critique of practical reason. Cambridge: Cambridge University Press.

Kant, I. (1998). [1785] Groundwork of the metaphysics of morals. Cambridge: Cambridge University Press.

Kant, I. (2000). [1797] The metaphysics of morals. Cambridge: Cambridge University Press. Korsgaard, C. (1996). The sources of normatively. Cambridge: Cambridge University Press. 
Korsgaard, C. (2005). Fellow creatures: Kantian ethics and our duties to animals. The Tanner Lectures on Human Values, 25, 77-110.

Korsgaard, C. (2011). Interacting with animals: A kantian account. In T. Beauchamp \& R. G. Frey (Eds.), The Oxford handbook of animal ethics. New York: Oxford University Press.

Kuba, M. (2010). A new method for studying problem solving and tool use in stingrays (Potamotrygon castexi). Animal Cognition, 13(3), 507-513.

Laland, K. (2003). Learning in fishes: from three-second memory to culture. Fish and Fisheries, 4(3), 199-202.

Nagel, T. (1978). The possibility of altruism. Princeton: Princeton University Press.

Reath, A., \& Timmermann, J. (2010). Kant's Critique of practical reason: A critical guide. Cambridge: Cambridge University Press.

Singer, P. (1999). Practical ethics (2nd ed.). Cambridge: Cambridge University Press.

Werner, M. (2003). Diskursethik als Maximenethik von der Prinzipienbegründung zur Handlungsorientierung. Würzburg: Königshausen und Neumann. 